Original Contribution

\title{
BEHAVIOUR OF BEEF BULLS REARED TOGETHER WITH LACTATING COWS AND CALVES ON A PASTURE/MEADOW COMPLEX
}

\author{
N. Markov ${ }^{1 *}$, T. Bozhanska ${ }^{1}$, I. Nedeva ${ }^{2}$ \\ ${ }^{1}$ Research Institute of Mountain Stockbreeding and Agriculture, Troyan, Bulgaria \\ ${ }^{2}$ Trakia University, Faculty of Agriculture, Department of Morphology, Physiology and Nutrition \\ of Animals, Stara Zagora, Bulgaria
}

\begin{abstract}
The behaviour of two groups of two bulls, lactating cows and calves from the Hereford and Limousin breeds was studied in the artificial pasture/meadow complex "Boyadzhievo" owned by the Research Institute of Mountain Stockbreeding and Agriculture on the outskirts of the town of Troyan. The complex is situated at $610 \mathrm{~m}$ above sea level, on a flat terrain with traditional grass. The meteorological characteristics of the late spring were studied, behavioural reactions were studied: grazing, rest, movement and acts of aggression.

Natural grassland, which is also the main source of food for the animals surveyed in the pasture complex, was rich in plant species, of which the largest share belonged to the group of forbs (55\%), followed by the group of cereals (38\%) and leguminous (7\%) grasses.

Atmospheric conditions and the botanical composition of the pasture had an influence on the ethological reactions of the studied animals. It was found that Index for functional activity (IFA) grazing of Hereford bulls was 0.45455 on pastures, cows -0.46934 at the time of the experiment and those of the Limousin breed -0.45448 , cows 0.47846 . The index of functional activity rest in bulls of both breeds on averages 0.50360 and cows 0.48144 .The acts of aggression for the research period were comparatively short: for Hereford bulls and cows 40 and 35 minutes respectively, and for the Limousin breed - 39 and 35 min. The most prolonged acts of aggression were those to motor vehicles, cars passing through and birds, and less pronounced were those to humans, dogs and wild game (foxes).
\end{abstract}

Key word: behavior, bulls, cows, pasture-meadow complex

\section{INTRODUCTION}

The intensification of cattle operations is a specific element of modern agriculture. In the different countries, the development of meattype cattle farming occurs under different conditions and is related to the behaviour of various breeds and categories of cattle. The regulated grazing on artificial pastures is organised by men and depends on the season and on sward amount and quality.

The behaviour is a mechanism of adaptation of animals to the environment, seasons and seasonal changes in vegetation and predators. For domestic animals and men, it is an important element of biocoenoses (1-4).

\footnotetext{
*Correspondence to: Nikolay Markov, Research Institute of Mountain Stockbreeding and Agriculture, 5600 Troyan, Bulgaria, email:ncm64@mail.bg
}

In grazing systems, calves lie down for 13 hours on the average, bulls - 12 hours and lactating cows -7 to 10 hours, divided in 5 intervals of about 1.5 hours (5).

Cattle are especially active at down and at sunset. They have a good feeding behaviour and exhibit a good growth, related to good productive performance (6-8) analysed the sensory systems in bulls. In their opinion the visual stimuli are the main triggers. The combined rearing of bulls and cows on the pasture has a beneficial effect on the behaviour of both genders.

The rearing of beef bulls is not associated with introduction of new technological elements, but their especially important position in the reproduction and group (herd) hierarchy requires study on their behaviour (9-13). 
MARKOV. N., et al.

(14) believed that a disadvantage of many ethological studies is the lack of uniform criteria for evaluation of animal behaviour. The comparison of data is almost impossible, as in most cases, they are of descriptive nature. According to (15) and (16) sward vegetation changes under the influence of natural and economic factors and this requires systemic care. On pastures, animals have an abundance of green grass that is rich in proteins, vitamins and minerals. The sexual activity of breeders is enhanced, semen production is increased and semen quality - improved.

The competent use of knowledge for the behaviour of animals does not allow the use of force methods and is integrally related to modern paradigms of cattle farming (17).

The aim of this study was to investigate the behavioural reactions of two pairs of bulls reared on pasture together with herds (groups) lactating cows with calved: grazing, rest (lying, standing, rumination), water intake, defecation, urination, as well as changed in their behaviour in the present of people, vehicles, agricultural machinery, dogs, birds and game.

\section{MATERIAL AND METHODS}

Study area

The study was carried out in the late spring of 2017 in the artificial pasture/meadow complex "Boyadzhievo" owned by the Research Institute of Mountain Stockbreeding and Agriculture on the outskirts of the town of Troyan. The pasture complex was surrounded with wire mesh (fence panels) and at some places, electric fences were used. In the complex, there were improved areas for hay first growth. The complex was situated at an altitude of $610 \mathrm{~m}$ on a terrain in the midPredbalkan.

The primary present sward comprised $38 \%$ cereal grasses, $7 \%$ leguminous grasses and $55 \%$ various grasses. The botanical composition was determined by collection of samples from $1 \mathrm{~m}^{2}$ from five randomly chosen areas.
According to the studies of (18), the proportion of leguminous grasses in the natural sward is low and varies from 2 to $8 \%$. In the experimental pasture/meadow complex, nitrogen-fixing crops (Birdsfoot Trefoil Lotus corniculatus L.; red clover - Trifolium pretense L. and white clover - Trifolium repens L.) were with the highest nutritional value and had a beneficial effect for obtaining a balanced ration. In this experiment, their part in the sward was very low (7\%) - result from specific requirements of the plants to environment and their lower stability.

Soil and climatic conditions in the region allowed for optimum development of different species and groups of forage crops. The botanical composition of the sward (Fig. 1) in the pasture complex was mainly represented by forbs $(55 \%)$ : rattle (Rhinanthus L.), полско scarlet pimpernel, (Anagallis arvensis L.), shepherd's purse (Capsella bursa-pastoris L.), yarrow (Achillea millefolium L.), broadleaf plantain (Plantago major L.), crested dog's-tail, (Cynosurus cristalatum L.), common bent (Agrostis capillaris L.), fescue (Festuca fallax L.), matgrass (Nardus stricta L.), couch grass (Agropyrum repens L.), wild carrot (Daucus carota L.), greater burdock, (Arctium lappa L.) etc .

Meteorological data were taken from the centre of the pasture/meadow complex. Data were from double daily readings (7.00 $\mathrm{h}$ and 21.00 h) of temperature ${ }^{\circ} \mathrm{C}$ (dry and wet thermometer), relative air humidity, wind velocity, colour cover and precipitations.

The average air temperature during the study period (detected by the dry and wet thermometers) was $15,6{ }^{\circ} \mathrm{C}$ with substantial amplitude $\left(8.7{ }^{\circ} \mathrm{C}-22.8^{\circ} \mathrm{C}\right)$. The relative air humidity was $78.7 \%$, and rainfall - low (2.7 $\mathrm{mm})$. The cloudiness at the time of the experiment was $6.3 \%$ (monthly average of $5.9 \%$ ) with average wind velocity of $1.8 \mathrm{~m} / \mathrm{s}$ (light air) Table 1.

Table 1. Climatic characteristic of the region in the studied period

\begin{tabular}{|l|c|c|}
\hline \multicolumn{1}{|c|}{ Indicators } & $\begin{array}{c}\text { Mean for the } \\
\text { period }\end{array}$ & $\begin{array}{c}\text { Mean for the } \\
\text { month }\end{array}$ \\
\hline $\begin{array}{l}\text { Temperature, }{ }^{\circ} \mathrm{C} \\
\text { min }\end{array}$ & 15,6 & 14.5 \\
\cline { 2 - 3 } $\max$ & 22.8 & 21 \\
\cline { 2 - 3 } Relative humidity, \% & 8.7 & 8.7 \\
\hline Cloudiness, \% & 78.7 & 79 \\
\hline Wind, $\mathrm{m} / \mathrm{s}$ & 6.3 & 5.9 \\
\hline Rainfall, mm & 1.8 & 1.6 \\
\hline
\end{tabular}


The pasture/meadow complex was located on an area of 13.33 ha and was used by two groups (herds) with two bulls each (adult and young), with adult bull age of 5 years and young bull age -2.5 years along with 10 lactating cows with calves in a herd (group) at a various age, from two meat-type breeds: Hereford and Limousin. The groups (herds) were separated by means of electric fence, and fenced area for each of groups was $0.4 \mathrm{ha}$. The used areas allowed a grazing front of $90 \mathrm{~m}$ to $120 \mathrm{~m}$, and groups (herds) returned to the centre of studied areas within 3 days and the cycle was repeated. Pathways passing through and around the pasture meadow complex were at an equal distance from both herds. Experimental animals were supplemented with concentrate in feeders within fenced areas at a daily amount of $1 \mathrm{~kg}$ per animal at a predefined time $-9.00 \mathrm{AM}$. Water intake occurred on the pasture itself from a trough supplied with water.

\section{Ethological indicators}

The animals were observed on the pasture over one week. The observation of behaviour was done from 7.00 to $19.00 \mathrm{~h}$ (during the day) and from 19.00 to $7.00 \mathrm{~h}$ (during the night). The bulls in each group (herd) were identified with numbers 1 and 2 by colour sprays. The same identification was applied to cows in groups (herds) with numbers from 1 to 10 using a spray with a different colour. Three main behaviours were observed: grazing; rest (lying, standing, rumination) and moving and thee frequency water intake; defecation; urination; changes in the behaviour of bulls and groups (herds) encountering men, vehicles, agricultural machinery, dogs, poultry, game (acts of aggression).

The weekly observation of animals allowed obtaining data about the rhythm of behavioural reactions. The latter were registered in protocols for each 24-hour period.

Ethological reactions were determined by chronometry (group chronometry) measuring the different acts by the modified method of (19) and (20).

The data are presented in graphs and tables.

\section{RESULTS AND DISCUSSION}

The farming of beef cattle on a pasture/meadow complex creates prerequisites for maximum utilization of the fresh green grass as main feed source.

The average values of behavioural acts of Hereford and Limousin bulls and cows are presented in Tables 2 and 3.

Table 2. Effect on studied functional activities (IFA) of Hereford bulls and cows reared in pasturemeadow complex

\begin{tabular}{|l|c|c|c|c|}
\hline \multirow{2}{*}{\multicolumn{1}{|c|}{ IFA }} & \multicolumn{2}{|c|}{ Hereford bulls } & \multicolumn{2}{c|}{ Hereford cows } \\
\cline { 2 - 5 } & Mean & \pm SEM & Mean & \pm SEM \\
\hline Grazing & $\mathbf{0 . 4 5 4 5 5}$ & 0.00084 & $\mathbf{0 . 4 6 9 3 4}$ & 0.00119 \\
\hline Resting: total & $\mathbf{0 . 5 0 3 6 3}$ & 0.00084 & $\mathbf{0 . 4 8 6 0 2}$ & 0.00086 \\
\hline including standing & 0.09788 & 0.00092 & 0.08424 & 0.00008 \\
\hline lying & 0.40575 & 0.00119 & 0.40179 & 0.00126 \\
\hline ruminating & 0.23142 & 0.00120 & 0.23200 & 0.00115 \\
\hline Moving & $\mathbf{0 . 0 4 1 8 2}$ & 0.00167 & $\mathbf{0 . 0 4 4 6 4}$ & 0.00110 \\
\hline
\end{tabular}

Table 3. Effect on studied functional activities (IFA) of Limousin bulls and cows reared in pasturemeadow complex

\begin{tabular}{|l|c|c|c|c|}
\hline \multirow{2}{*}{\multicolumn{1}{c|}{ IFA }} & \multicolumn{2}{|c|}{ Limousin bulls } & \multicolumn{2}{c|}{ Limousin cows } \\
\cline { 2 - 5 } & Mean & \pm SEM & Mean & \pm SEM \\
\hline Grazing & $\mathbf{0 . 4 5 4 4 8}$ & 0.00103 & $\mathbf{0 . 4 7 8 4 6}$ & 0.00140 \\
\hline Resting: total & $\mathbf{0 . 5 0 3 5 6}$ & 0.00048 & $\mathbf{0 . 4 7 6 8 5}$ & 0.00024 \\
\hline including standing & 0.08884 & 0.00032 & 0.06360 & 0.00029 \\
\hline lying & 0.41009 & 0.00095 & 0.41325 & 0.00270 \\
\hline including ruminating & 0.23579 & 0.00012 & 0.23373 & 0.00189 \\
\hline Moving & $\mathbf{0 . 0 4 1 8 2}$ & 0.00092 & $\mathbf{0 . 0 4 4 7 0}$ & 0.00187 \\
\hline
\end{tabular}


During the observation period, Hereford bulls spent $10.33 \mathrm{~h}$ grazing, IFAG -0.45455 (Index functional activity grazing) and cows -11.08 $\mathrm{h}$, IFAG - 0.46934. For the same period, Limousin bull spent $10.4 \mathrm{~h}$ (IFAG - 0.45448) grazing and cows $-11.28 \mathrm{~h}$ (IFAG -0.47846$)$. The animals from both herds grazed in a fanlike pattern in a group, at a distance $8-10 \mathrm{~m}$ each from the other. It was suggested that the duration of grazing was specifically related to meteorological conditions and available sward composition on the pasture/meadow complex. Similar results were obtained by (11) and (3).

During the rest, a certain difference in indexes was observed. The rest for Hereford bulls was 0.50363 vs 0.48602 for cows. Similar timing was present for Limousin bulls - IFAR (Index functional activity rest) is 0.50356 and cows 0.47685 . It was found out that the difference was due to the time spent standing as male animals rested significantly more than females. The cattle from both groups (herds) rested in the periphery of the pasture/meadow complex during the day and in its centre in the evening. The cows rested lying in a horseshoe-like
MARKOV. N., et al. fashion, with calves lying in the centre of the horseshoe. Bulls rested in the periphery of the herd (group).

The values of the other behavioural reactions e.g. lying, rumination, moving, water intake and defecation were fairly similar. When the calved suckled, the cows were standing and ruminating.

During the observation period, calves were fed by dams 4-6 times during the light part of the day and twice at night. The occasional grazing occurred at no more than 4-5 m away from their mothers. In both breeds, episodes of playing were observed 3-4 times during the 24hour period. All these behavioural acts occurred under constant supervision from the two bulls in groups (herds). Similar reactions were reported by $(1,8,12)$.

Aggression acts during the study period (Figures 1 and 2) were relatively short: 40 min for Hereford bulls and $35 \mathrm{~min}$ for Hereford cows, and $39 \mathrm{~min}$ and $35 \mathrm{~min}$ for Limousin bulls and cows, respectively.

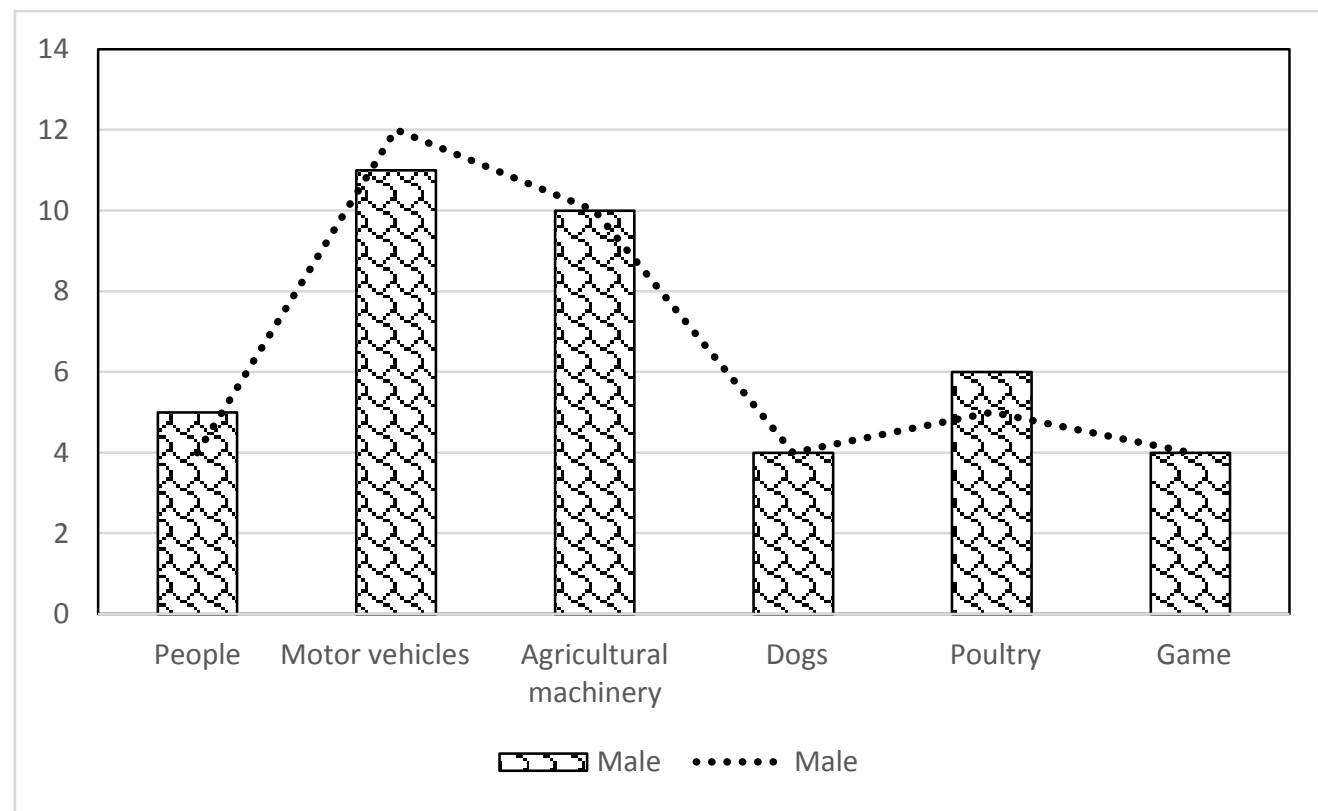

Figure 1. Acts of aggression- Male

The active defensive behaviour began with the aggression from the part of the older bull, followed by the younger bull, expressed with mooing (sound signal), kicking and rising of the head, and very fast subsequent attack with bent head and running towards the irritant. This behaviour was gradually transmitted to the entire herd (group). Passive-defensive behaviour was mainly observed during contact with people. The most prolonged acts of aggression were exhibited against motor vehicles, passing cars and birds (flocks of gray crows). Less pronounced, in terms of duration and frequency, were acts exhibited towards humans, dogs and game (foxes). Such relationships between acts of cattle reared on pastures were reported by (21), and (3). 


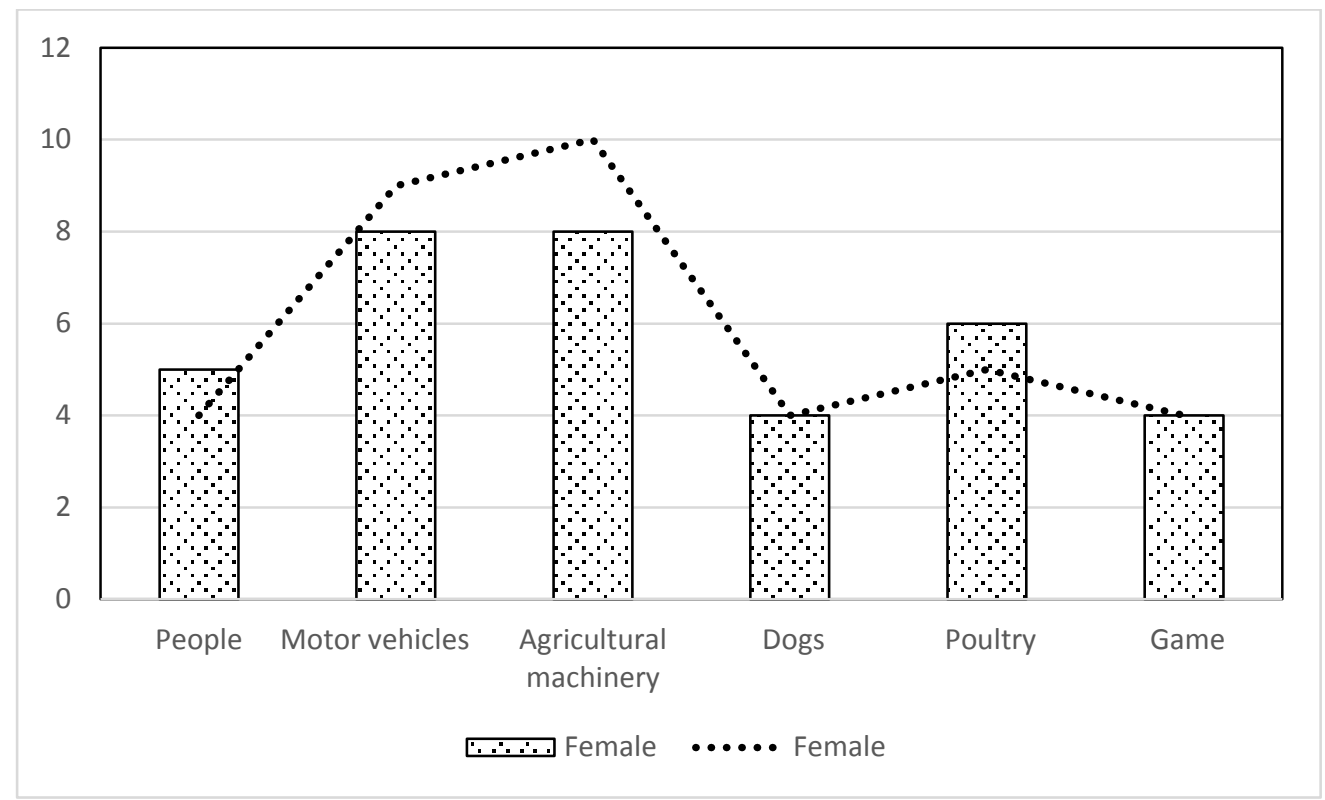

Figure 1. Acts of aggression- Female

Occupied spaces are a main indicator of animal behaviour. The different reactions occurred at a various distance. The highest distance is that of a man as irritant, $80-100 \mathrm{~m}$, whereas the lowest distance - the appearance of tractor or motor vehicle, $10-15 \mathrm{~m}$. In our view, this is attributed to a conditional reflex in observed animals as they associated the appearance of machinery with feeding. The other distances have medium values. Similar distances associated with defense reactions and aggression in cattle were reported by $(8,13)$ and (3).

\section{CONCLUSIONS}

The time spent grazing depends on the season, amount and quality of present sward at the pasture/meadow complex. Hereford bulls spent 10.33 hours on pastures, cows -11.08 hours at the time of the experiment and those of the Limousin breed - 10.40 hours, cows 11.28 hours.

The ratio between grazing: rumination times in Hereford bulls was 1.96:1, and in Limousin bulls - 1.94:1. In cows, the ratio was 2.02:1 (Hereford breed) and 2.04:1 (Limousin breed).

The acts of aggression for the research period were comparatively short: for Hereford bulls and cows 40 and 35 minutes respectively, and the Limousin breed - 39 and $35 \mathrm{~min}$. The most prolonged acts of aggression were those to motor vehicles, cars passing through and birds, and less pronounced were those to humans, dogs and wild game (foxes).
The distance to objects in relation to the threshold of irritation was different.

\section{ACKNOWLEDGEMENTS}

The authors are thankful to the authorities of the Research Institute of Mountain Stockbreeding and Agriculture - Troyan, for the material and logistic support.

\section{REFERENCES}

1. Petkov A., Enev E., K. Sivkova, I. Vrliyakov, N. Clouzov, Behavior of Animals, CD Kota, Stara Zagora, 59-59, 1999

2. Nikolov V., Ethological Aspects of Selection, II, Selection Aspects, Animal Breeding Sciences, 3-4, p.118-122, 1999

3. Baskin, L. \& Chukurova E. Cattle behaviour, Galleya-print, Moscow, $78(\mathrm{Ru})$, 2014

4. Stoycheva, Sv. Ethological and physiological aspects of the relationship mother-new-born in goats of Bulgarian White Milk breed and their cross-breeds Ethological and physiological aspects in the relation of mother-newborn in BBM goats and their crosses, Doctoral dissertation, Agricultural Academy (Bg), 2014

5. Phillips, C. Cattle behavioor and welfare blackmell, Science, Oxford, UR, 257, 2002

6. Albright, J. \& Arave C.W. The Behaviour of Cattle, $\mathrm{CAB}$ International, Cambridge, UK, 1, 1997

7. Hale, E., Journal Science, 25, pp.36-43, 1966

8. Motuzko, N. \& Nikitin Yu. Physiological 
basis of the ethology of livestock, 11-23 (Ru), 2003

9. Hinkovski, Ts., Shabalina A., Tomova Y., Rusev N. \& Konstantinov N. Behaviour of cattle under industrial conditions, Review, Sofia, Agrohrananform, 65-67, 1981

10. Varlyakov, I., D. Dinev, V. Radev, T. Slavov, Ethological evaluation of large measured building for dairy cows reared in individual cubicles. Trakia Journal of Sciences, Vol. 5, №1, 52-58, 2007

11. Yonikovski, M., Todorov, M. \& Stankov I. Behaviour of lactating beef cows on a sown pasture, Journal of Mountain on the Balkans, 11(3), 421-433, 2008

12. Varlyakov, I., V. Radev, T. Slavov, N. Grigorova, Ethological evaluation of a building for free housing of dairy cows. I. Behavioral activities in the summer. Trakia Journal of Sciences, Vol. 8, Suppl. 1, 222229, 2010

13.Varlyakov, I., Radev, V., Slavov, T. \& Grigorova, N. Behaviour of cows in milking parlour, Agriculture Science and Technology, 3(2), 107-111, 2011

14.Kudrin, A., Sugunova T. \& Britvina I. Ethological individuality as an indicator of breeding Ayrshirskogo livestock, Dairy farming newspaper, №12, 32-33 (Ru), 2016
MARKOV. N., et al.

15.Klijn, H. ALA, № 9, 4103, 1976

16.Nenov, Ts. Hygiene and technologies in industrial stockbreeding, Zemizdat, Sofia, 112-114 (Bg), 1985

17.Grandin, T. Welfare of cattle during slaughter and the prevention of nonambulatory (dovner) cattle, J. Vet. Med. Asos., 219, 1377-1382, 2001

18.Kirilov, A., P. Todorova, Development of forage areas and forage resources in Bulgaria during the period of transition. In: Land use systems in grassland dominated regions, Eds. A. Luscher, B.Jeangros, W. Kessler, O. Huguening, M.lobsiger, N.Millar and D.Suter. Grassland Science in Europe, 9: 855-857, 2004

19.Velikzhanin, V., Vasileva E. \& Kulikov V. Metodical recommendations in behavioural study of livestock, Leningrad, 15-34 (Ru), 1975

20.Velikzhanin, V. Metodical recommendations in using ethological indicators dairy cattle breeding, Sankt Peterburg, $19(\mathrm{Ru}), 2000$

21.Varlyakov, I., T. Slavov, N. Grigorova, Ethological evaluation of a building for free housing of dairy cows. II. Behavioural activities in the winter. Agricultural Science and Technology, vol.2, № 1, 14-21, 2010 